\title{
Autonomous and nonautonomous regulation of axis formation by antagonistic signaling via 7-span CAMP receptors and GSK3 in D ictyostelium
}

\author{
Gail T. Ginsburg' and Alan R. Kimme' ${ }^{2}$ \\ Laboratory of Cellular and Developmental Biology, National Institute of Diabetes, Digestive, and Kidney Diseases, $\mathrm{N}$ ational \\ Institutes of Health, Bethesda, M aryland 20892-2715 USA
}

\begin{abstract}
Early during D ictyostel ium development a fundamental cell-fate decision establishes the anteroposterior (prestalk/ prespore) axis. Signaling via the 7-transmembrane CAMP receptor CAR4 is essential for creating and maintaining a normal pattem; car4-null alleles have decreased levels of prestalk-specific mRNAs but enhanced expression of prespore genes. car4 ${ }^{-}$cells produce all of the signals required for prestalk differentiation but lack an extracellular factor necessany for prespore differentiation of wild-type cells. This secreted factor decreases the sensitivity of prespore cells to inhibition by the prestalk morphogen DIF-1. At the cell autonomous level, CAR4 is linked to intracel lular circuits that activate prestalk but inhibit prespore differentiation. The autonomous action of CAR4 is antagonistic to the positive intracellular signals mediated by another CAMP receptor, CAR1 and/or CAR3. Additional data indicate that these CAR-mediated pathways converge at the serine/threonine protein kinase GSK3, suggesting that the anterior (prestalk)/posterior (prespore) axis of Dictyostelium is regulated by an ancient mechanism that is shared by the Wnt/Fz circuits for dorsoventral patteming during early Xenopus development and establishing D rosophila segment polarity.
\end{abstract}

[Key Words: GSK3; development; PKA; gene expression; pattern formation]

Received March 27, 1997; revised version accepted June 25, 1997.

Pattern formation in developing multicel lular organisms is regulated, in part, through coordinated response to multiple extracel lular signals. The proportions and positions of distinct cells result from interactions among activating and inhibiting pathways. Experimental manipulation of these signal-response circuits can often redirect cell fate. This is evident in forming the dorsoventral axis during early Xenopus laevis embryogenesis and in establishing segment polarity in Drosophila melanogaster, where duplicated axes or expanded anteroposterior boundaries, respectively, can be manifest (see Perrimon 1994; Miller and Moon 1996). A fundamental dichotomy during the early differentiation of Dictyostelium discoideum establishes the prestalk/prespore pattern, an anteroposterior organization that is also regulated by cell-cell communication and intracellular responses. Also common to these systems is their mechanisms for control by secreted morphogens. For Dictyostelium, it has been known for nearly a decade that devel opment is regulated by the extracellular morphogen CAMP and a

${ }^{1}$ Present address: National Institute of Allergy and Infectious Diseases (NIAID), National Institutes of Health, Bethesda, Maryland 20892 USA. ${ }^{2}$ Corresponding author.

E-MAIL ark1@helix.nih.gov; FAX (301) 496-5239. family of serpentine, G protein-coupled receptors. M orphogen concentration is regulated by another secreted factor, phosphodiesterase (see Kimmel and Firtel 1991). More recently, the Drosophila frizzled2 (fz2) and smoothened genes were suggested to encode presumptive serpentine receptors for signaling via the morphogens Wingless (Wnt/Wg) and Hedgehog, respectively (Alcedo et al. 1996; Bhanot et al. 1996; Perrimon 1996; van den Heuvel and Ingham 1996). Wnt concentration, in turn, is sensitive to the secreted, Fz-related proteins Frizzled in bone (Frzb) and Frizzl ed-related protein (FRP) (Leyns et al. 1997; Wang et al. 1997; J. Rubin, X. He, and H. Varmus, pers. comm.).

Dictyostelium grow vegetatively as ameboid cells, but begin a muticellular developmental cycle involving aggregation, cell differentiation, and morphogenetic movement when nutrients are depleted (Kimmel and Firtel 1991; Firtel 1995). As multicellular structures form, nonterminally differentiated prestalk and prespore cells appear. These cells sort into a defined pattern, configuring a tip of prestalk A cells atop a mound comprised primarily of prespore cells. Scattered among these latter cells are the anterior-like cells (ALCs), a subset of prestalk cells. The tipped mound elongates, falls to the substratum, and forms a pseudoplasmodium, or migrating slug, 
that retains the original cell pattern. Prestalk A cells localize to the anterior of the slug while the prespore cells and ALCs are found toward the rear (see Williams 1995). These progenitor cells eventually give rise to the terminally differentiated vacuolized stalk cells and the heat-resistant spores found in mature fruiting bodies at culmination, the terminal stage of development. The cellular pattern of the fruiting body can thus be traced from a pattern established in the aggregation mound.

Extracellular CAMP is a primary regulatory signal for Dictyostelium development (Kimmel and Firtel 1991; Firtel 1995). The receptors for CAMP belong to the serpentine, seven-transmembrane family and are localized at the cell surface, coupled with $G$ proteins. CAMP is the chemoattractant that directs aggregation, but signaling is also requi red for differentiation, morphogenetic movement, and pattern formation (Klein et al . 1988; Saxe et al. 1993; Louis et al. 1994). There are four CAMP receptor (CAR) subtypes in Dictyostelium encoded by single-copy genes (Saxe et al. 1991a,b, 1993; Johnson et al. 1993; Louis et al. 1994; Ginsburg et al. 1995). Each has a distinct temporal and spatial pattern of expression and each is associated with specific developmental functions. CAR1 is expressed first and is required for the earliest developmental events (Klein et al. 1988; Saxe et al. 1991a,b; Sun and Devreotes 1991; Louis et al. 1993). It is essential for establishing and propagating waves of CAM $P$ that define aggregation territories and for promoting early developmentally regulated gene expression. Cells that lack CAR 1 fail to aggregate or activate cellspecific gene expression (Klein et al. 1988; Sun and Devreotes 1991), but CAR3 may substitute for CAR1 during differentiation in suspension culture if car $^{-}{ }^{-}$cells are provided with an exogenous source of CAM P (Pupillo et al. 1992; Insall et al. 1994; Soede et al. 1994). CAR1 and CAR3 have a high affinity for CAMP, whereas CAR2 and CAR4, which are expressed later during development and are involved in pattern formation, have significantly lower affinities (Johnson et al. 1992; Saxe et al. 1993; Louis et al. 1994; J.M. Louis and A.R. Kimmel, unpubl.).

The appearance of the late, low-affinity receptors parallels the dramatic rise in extracellular CAMP that follows aggregation (A be and Yanagisawa 1983). In a manner analogous to that of car $1^{-}$mutants, car2 null alleles also exhibit developmental arrest (Saxe et al. 1993). Although car2- ${ }^{-}$cells aggregate and initiate differentiation, development arrests at the mound. car4 ${ }^{-}$cel Is have more subtle defects in differentiation, no doubt reflecting the multiple and complex controls of differentiation by transmembrane signaling via the other CAMP receptors (Louis et al. 1994). CAR4 is expressed initially in multicellular aggregates and remains expressed through culmination (Louis et al. 1994). Expression of CAR4 is maximal in prestalk A cells with lower but detectable levels in prespore cells (Louis et al. 1994). CAR4 is also the primary low-affinity CAR in the ALC population (Louis et al. 1994; Ginsburg et al. 1995). car4 null slugs have decreased expression of prestalk-specific ecmA and ecmB mRN As and barely detectable expression of ALC markers. Prespore differentiation is al so misregulated in car4 null alleles. Prespore markers are overexpressed in these mutants, and prespore cells are additionally detected in canonical prestalk regions of the slug and within the stalk tube.

We now demonstrate that CAR4 regulates prestalk and prespore differentiation by distinct mechanisms and that CAMP signal responses function through both cell autonomous and nonautonomous pathways. In particular, CAR4 activation of intracellular (cell autonomous) signaling stimulates prestalk but inhibits prespore differentiation. Because CAMP is also required for prespore differentiation, CAR4 acts autonomously and antagonistically to positive regulatory signal s mediated by another CAMP receptor, CAR1 and/or CAR3. We present evidence that these distinct CAR-mediated pathways converge to regulate GSK3 activity, an essential component for establishing prestalk/prespore patterns in Dictyostelium (Harwood et al. 1995). Thus, regulation of the anteroposterior axis in Dictyostelium by intracellular signaling via the seven-span CARs shares mechanisms for pattern formation with Drosophila and Xenopus by the Wnt/Wg morphogens and their seven-span Fz receptors and may derive from an ancient pathway for establishing body plan.

\section{Results}

Cell-specific gene expression in car4 null cells

Figure 1 shows representative developmental RNA blots of car4- ${ }^{-}$and wild-type cells, using the prestalk marker ecmA and the prespore marker cotB (see Louis et al. 1994). Gene expression in the major cell populations is differentially affected by mutation of CAR4. Expression of prespore (e.g., cotB) genes is increased significantly in the mutants, whereas prestalk (e.g., ecmA) expression is reduced. As $\sim 80 \%$ of cells during development are prespore, the increase in cotB expression observed in car4cells cannot result from a simple alteration of cell-type ratios and recruitment of prestalk cells into the prespore pathway. Additional mechanisms must be involved. Be-

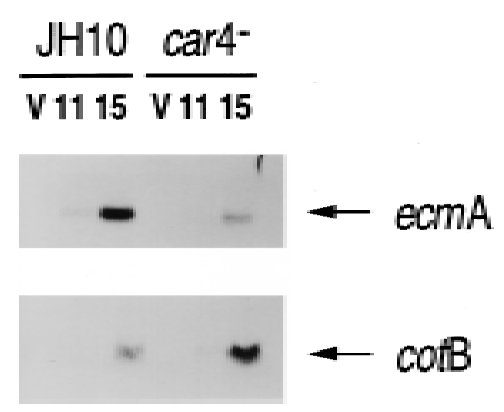

Figure 1. Cell type-specific gene expression in wild-type and car4 null cells. Wild-type JH10 and car4 null cells were harvested from vegetative growth (V) and plated for synchronous development. At hours indicated, RN As were isolated and hybridized on N orthern blots to the prestalk probe ecmA and the prespore probe cotB. 
cause several extracellular factors (most notably CAMP, adenosine, and DIF-1; see Schaap 1991 and below) will stimulate or inhibit cell-specific gene expression during Dictyostelium development, we investigated whether car4 mutants accumulate or respond to these factors abnormally.

\section{CAMP and DIF-1 production in car4 ${ }^{-}$cells}

Secreted CAMP directs aggregation and prestal $k$ and prespore cell differentiation (Kimmel and Firtel 1991). From aggregation through slug formation of wild-type cells there is a progressive increase in CAMP levels and an accompanying regul ated expression of different receptors with decreasing affinities for CAMP (A be and Yanagisawa 1983; Johnson et al. 1992; Ginsburg et al. 1995; J.M. Louis and A.R. Kimmel, unpubl.). Wild-type and the car4 null strains were developed in paral lel and accumulated CAMP levels measured at stages of development that normally express CAR4 protein. The car4 null alleles have reproducibly $30 \%-60 \%$ lower levels of CAMP than do equivalent wild-type organisms (A.R. Kimmel, unpubl.). However, the CAMP dose-response requirements for prestalk (ecmA) and prespore (pspA) mRN A induction in culture (Soede et al . 1996) cannot account for the large disparity observed for cell-specific gene expression between wild-type and car4- cells (see below).

DIF-1 is a secreted factor essential for normal prestalk/ stalk cell differentiation but an effective inhibitor of prespore expression (Williams et al. 1989; Berks and Kay 1990). Using a bioassay for DIF-1 (Kay 1987), we show that the levels of DIF-1 from car4- and wild-type cells cultured without CAMP are biologically comparable, as are the CAMP-induced accumulations of DIF-1 in the two cultures (Table 1). M ore specifically, DIF-1 levels in the mutant cultures are sufficient for maximal prestalk (e.g., ecmA) induction and prespore (e.g., cotB) repression (Berks and Kay 1990).

Because the DIF-1 bi oassay is very sensitive to artifactual inhibition, we also monitored DIF-1 synthesi s in the presence of CAM P by in vivo precursor radiolabeling (Kay et al. 1992). Under these conditions, production of DIF-1 dechlorinase, the enzyme responsi ble for initiating DIF-1 degradation, is inhibited in both wild-type (Insall et al. 1992) and car4- cell lines (R.R. Kay and A.R. Kimmel, unpubl.). As seen in Figure 2, DIF-1 syntheses are biologically equivalent (within $~ 50 \%$ ) in both cell lines. Thus, the differentiation defects of car4 null alleles are not attributable simply to deficiencies in the production of the prestalk morphogen DIF-1 (or of CAMP).

Table 1. DIF-1 production in car4 null cells

\begin{tabular}{lcc}
\hline & \multicolumn{2}{c}{ Units of DIF-1 $10^{6}$ cells } \\
\cline { 2 - 3 } & -CAMP & +CAMP \\
\hline Wild type & 0.3 & 45 \\
car4 $^{-}$ & 0.4 & 22 \\
\hline
\end{tabular}

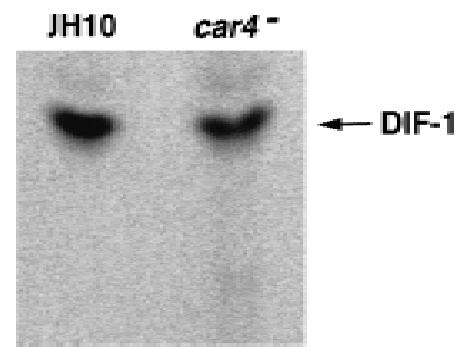

Figure 2. Synthesis of DIF-1 during differentiation of wild-type and car4 ${ }^{-}$cells. Wild-type JH10 and car4 null cells were differentiated in suspension culture with $1 \mu \mathrm{Ci} / \mathrm{ml}$ of ${ }^{36} \mathrm{Cl}$. For the first $5 \mathrm{hr}, \mathrm{CAMP}$ was added at 6-min intervals to a final concentration of $30 \mathrm{~nm}$. Subsequently, cultures were left untreated or adjusted to $300 \mu \mathrm{M}$ cAM P. Cells and medi a were extracted twice with 1 volume of hexane, and extracts were pooled, dried, resuspended in ETOH, and analyzed by thin layer chromatography. Radiolabeled DIF-1 was identified by comigration with purified DIF-1. Quantification by Phosphorlmager analyses yiel ded differences in DIF-1 accumulation of $\sim 50 \%$ between the two strains.

Autonomous defects for CAMP signal response in car4- ${ }^{-}$cells

Figure 3A outlines briefly our approach for anal yzing differentiation in suspension culture in the presence or absence of exogenous regulatory factors. To initiate differentiation and stimulate expression of the essential CAM $P$ receptor CAR 1, cells are washed from growth media and then pulsed with $30 \mathrm{~nm} \mathrm{CAMP}$ for $5 \mathrm{hr}$ (Kimmel 1987; Ginsburg and Kimmel 1989). When cultures are then maintained at a saturating level of CAMP (>300 $\mu \mathrm{M})$, late developmental events including the induction of cell type-specific gene expression are stimulated (Louis et al. 1993).

As seen in Figure 3B, the addition of CAM P to suspension cultures does not rescue the altered patterns of gene expression observed for car4- cells (see Fig. 1); prestalk ecmA expression is low, whereas the prespore cotB mRNA is overexpressed as compared with the wild-type (JH10) controls. Adenosine is a competitive inhibitor of CAMP binding to CAR1 (Theibert and Devreotes 1984) and, in wild-type cells, will suppress prespore expression and stimulate prestalk expression in the presence of added CAMP (Spek et al. 1988; Schaap 1991). Figure 3B also shows that addition of adenosine to CAMP-treated car4 null alleles does not reduce prespore cotB expression to wild-type levels, nor will depletion of adenosine from wild-type cul tures by treatment with adenosine deaminase (ADA) increase expression levels to that of the car4- ${ }^{-}$cells. Similarly, adenosine does not rescue prestalk ecmA gene expression in cAM P-treated car4- cells. N ot surprisingly, the car4 null alleles appear to have an inherent defect in CAMP response (i.e., cell autonomy), suggesting that in wild-type cells CAR4 is a positive regulator of prestalk gene expression but is coupled to an inhibitory pathway for prespore differentiation.

As expected, growing cells, cAMP-pulsed cells, and cells differentiated for only $2 \mathrm{hr}$ with CAM P and/or DIF-1 

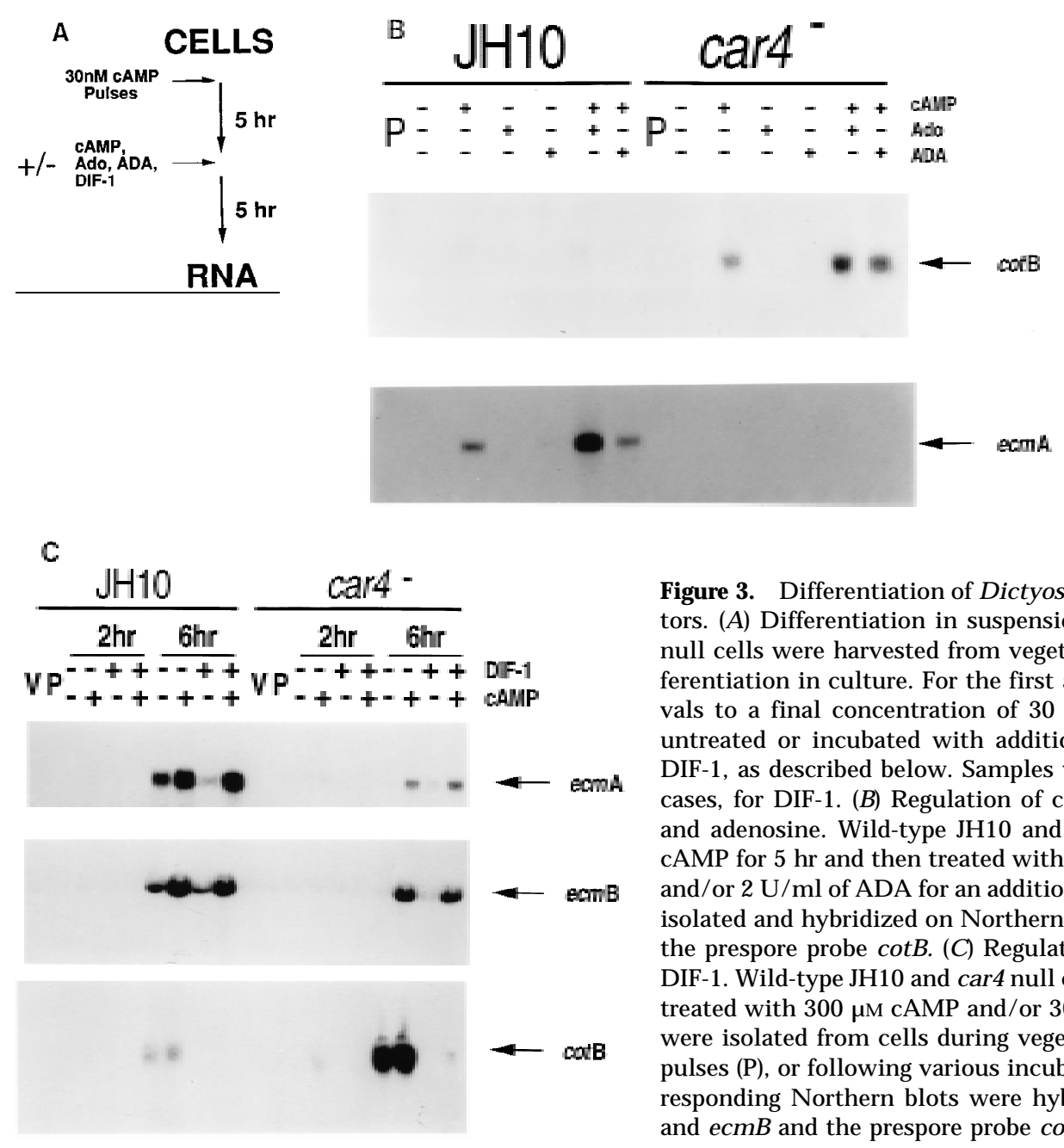

Figure 3. Differentiation of Dictyostelium with exogenous regulatory factors. (A) Differentiation in suspension cultures. Wild-type JH10 and car4 null cells were harvested from vegetative growth and resuspended for differentiation in culture. For the first $5 \mathrm{hr}$, cAMP was added at 6-min intervals to a final concentration of $30 \mathrm{~nm}$. Subsequently, cultures were left untreated or incubated with additional CAMP, adenosine, ADA, and/or DIF-1, as described below. Samples were extracted for RNA and, in some cases, for DIF-1. (B) Regulation of cell-specific gene expression by CAMP and adenosine. Wild-type $\mathrm{JH} 10$ and car4 null cells were pulsed $(\mathrm{P})$ with CAM P for $5 \mathrm{hr}$ and then treated with $1 \mathrm{~mm}$ CAMP, $10 \mathrm{~mm}$ adenosine (Ado), and/or $2 \mathrm{U} / \mathrm{ml}$ of ADA for an additional $5 \mathrm{hr}$, as described in A. RN As were isolated and hybridized on $\mathrm{N}$ orthern blots to the prestalk probe ecmA and the prespore probe cotB. (C) Regulation of cell-specific gene expresion by DIF-1. Wild-type JH 10 and car4 null cells were pulsed with CAMP and then treated with $300 \mu \mathrm{M}$ CAM P and/or 300 nM DIF-1, as described in A. RNAs were isolated from cells during vegetative growth (V), after $5 \mathrm{hr}$ of CAMP pulses $(\mathrm{P})$, or following various incubations after pulsing as indicated. Corresponding $\mathrm{N}$ orthern blots were hybridized to the prestalk probes ecmA and ecmB and the prespore probe cotB.

have only low levels of prestalk (ecmA and ecmB) and prespore (cotB) mRN As (see Fig. 3C). By 6 hr of culture in the absence of additional CAMP, cell type-specific $\mathrm{mR}$ NAs begin to accumulate; car4- cells consistently exhibit lower levels of prestalk ecmA and ecmB expression and higher levels of prespore cotB expression than do parental cells.

Under the culture conditions described, both DIF-1 and CAMP are required for prestalk gene expression. DIF-1 or CAM P, added separately or in combination, cannot rescue prestalk gene expression in car $4^{-}$cells. CAM P will stimulate DIF-1 accumulation (see Table 1), suppress production of DIF-1 dechlorinase, and, hence, induce prestalk gene expression to levels equivalent to those observed with CAM P +DIF-1 [at 300 nM (Fig. 3C)].

If $300 \mathrm{~nm}$ DIF-1 is added during differentiation (see Fig. $3 A$ ), activated expression of cotB by CAMP in wild-type and car4- cells is similarly repressed (Fig. $3 \mathrm{C}$ ). Thus, the high levels of prespore gene expression in car4- cells are not the result of a diminished inhibitory response to DIF-1. $\mathrm{N}$ either are they attributable to an inability to accumulate sufficient levels of DIF-1 for normal cell-specific regulation (see Table 1, Fig. 2). Consistent with previous data, the delayed accumulation of DIF-1 during CAM P-induced differentiation, in contrast to the effect of DIF-1 treatment at the onset of differentiation, is inadequate to effect prespore repression in either wild-type or car4 null cells.

Pattern formation in developmental chimeras of wild-type and car4 ${ }^{-}$cells

Dictyostelium is well suited for study of cell autonomy in developmental chimeras. Strains with equivalent competence for aggregation will form mounds comprised of both cell lines (Loomis 1993). Evaluation of differentiation can reveal the devel opmental autonomy of individual strains or their cooperative interactions. Wildtype and car4 mutant cells were marked with cell-type specific promoters fused to lacZ, mixed at a ratio of 1:9 with unmarked populations, and developed as chimeric organisms. Developmental patterns of $\beta$-galactosidase staining were compared among homologous and heterol ogous mixes to determine whether aberrant patterns of car4 null cells could be rescued by a predominant wildtype background or, conversely, whether wild-type cells developed abnormally with mutants. 
Figure 4A shows chimeric prestalk patterns with wildtype cells and car4 mutants marked with the prestalk ecmA/lacZ. Homologous mixes look identical to that described previously for $100 \%$ marked populations (Louis et al. 1994). In wild-type, $\beta$-galactosidase is stained prominently in the prestalk $A$ zone at the anterior of the slug but also weakly throughout the posterior region, the result of ecmA expression in the ALC prestalk population. Levels of ecmA mRNA in car4 null cells, $\beta$-galactosidase staining is diminished in the slug anterior and is all but absent in the ALC population in the homologous car4 null chimera. This phenotype is not rescued in the chimeras with $90 \%$ wild-type cells. The absence of CAR4 protein defines a cell autonomous defect in prestalk differentiation. In contrast, ALCs of marked wild-type cells, developed as a chimeric mix with $90 \%$ unmarked car4 cells, have significant ecmA expression. These data suggest that car4 null cells produce all of the signals required for wild-type prestalk differentiation, but they lack an intracellular response normally regulated by CAR4 and required by prestalk cells.

Regulation of prespore patterns in developing chimeras is opposite that of prestalk (Fig. 4B). Patterns of homologous mixes using prespore cotB/lacZ appear identical to that of $100 \%$ marked cells (Louis et al . 1994). For wild-type, no $\beta$-gal actosi dase staining is detected in the anterior, prestalk A zone; car4- controls show expansion of cotB/lac Z expression and comingling with prestalk cells in the anterior region. In contrast, when car4- cells are devel oped with $90 \%$ wild-type cells, the mutant cells form a normal prespore pattern. Wild-type cells position abnormally in an organism comprised of $90 \%$ car4 null cells but retain their cell-specific pattern of expression (see Louis et al. 1994). Thus, prespore patterning (but not prespore gene expression, see below) is regulated nonautonomously by the genotype of the predominant cell in the chimeric organism.

Autonomous and nonautonomous defects of car4 null alleles in cell-specific differentiation

The development of chimeras using cell-specific markers suggests a combination of autonomous and nonautonomous mechanisms for CAR4 regulation of prestalk and prespore differentiation. To study this further, we examined the ability of car4- ${ }^{-}$and wild-type cells to contribute to the major cell populations of terminally developed chimeras. Two modifications were made. First, we used the ubiquitous promoter actin 15 (act15) to trace the fate of all cells. In addition, we present staining patterns of fully devel oped fruiting bodies, whereterminally

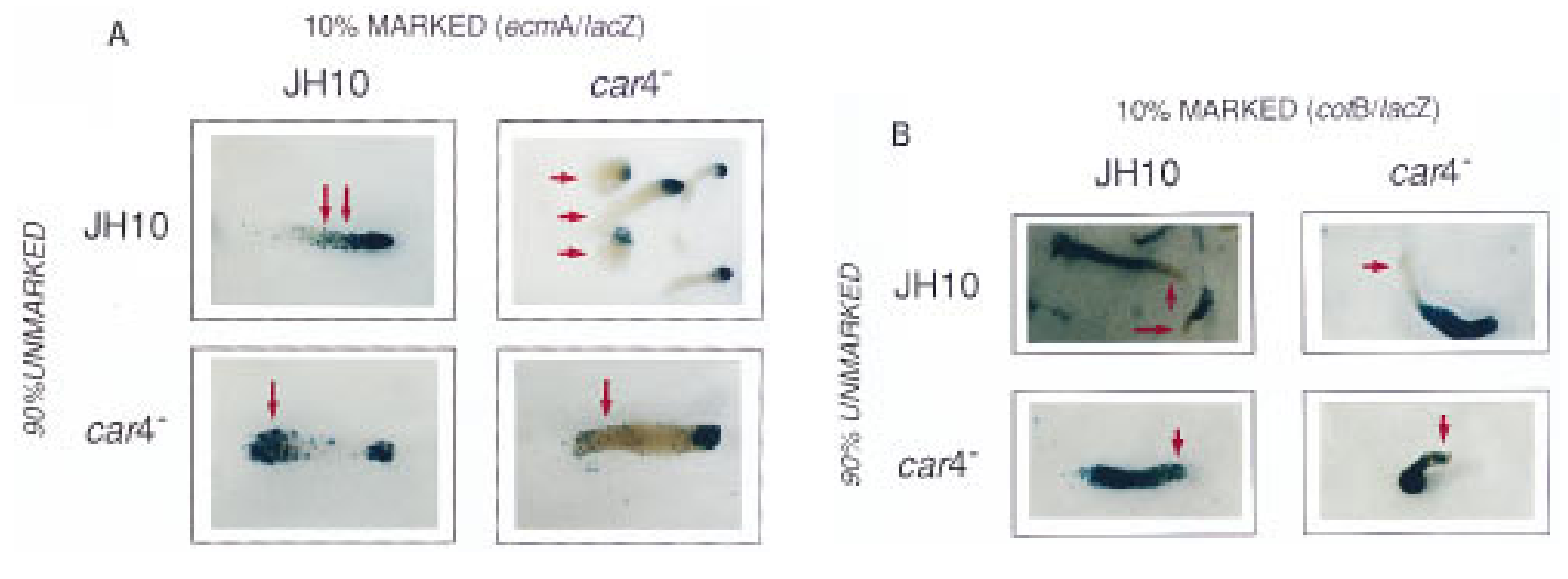

C

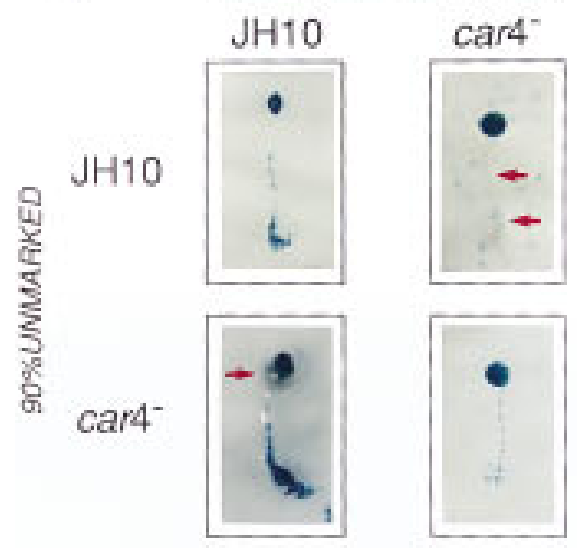

Figure 4. Patterning in developmental chimeras. (A) Chimeras with ecmA/lacZ marked cells. $\beta-G$ alactosi dase staining of various chimeric mixes of unmarked cells and cells carrying the prestalk ecmA/lacZ transgene at 9:1 ratios, respectively, as indicated. Arrows depict differences in prestalk ALC staining in slug posteriors among the different chimeras. (B) Chimeras with cotB/lacZ marked cells. $\beta$-Galactosidase staining of various chimeric mixes of unmarked cells and cells carrying the prespore cotB/lac $Z$ transgene at 9:1 ratios, respectively, as indicated. Arrows depict differences in prespore staining in the slug anteriors among the different chimeras. (C) Chimeras with act15/ lacZ-marked cells. $\beta$-Galactosidase stainings of various chimeric mixes of unmarked cells and cells carrying the ubiquitous act15/lacZ transgene at 9:1 ratios, respectively, as indicated. A rrows depict differences in staining of fruiting bodies among the different chimeras. car4- cells fail to populate the stalk when mixed with wild-type JH 10 cells. JH10 cells fail to form spores when developed with car4 null cells but contribute primarily to the stalk tube and and prestalk derived upper cup that is localized atop the spore mass. 
differentiated spores and stalk cells are easily distinguished; identical fates were seen with migrating slugs.

In Figure 4C, IacZ expression is seen throughout the spore masses and supporting stalk tubes of the $\mathrm{JH} 10$ and car4- homologous controls. However, when act15/lacZmarked car4- ${ }^{-}$cells were devel oped with a background of wild-type cells, most mutant cells are recruited to a prespore/spore pathway. Little staining is seen in the stalk, indicating that car4 mutants have an inherent (cell autonomus) defect in prestalk, but not prespore, differentiation. Wild-type cells, on the other hand, contribute primarily to prestalk/stalk structures (they form only few spores) in chimeras with $90 \%$ car4 null cells. car4 null cells produce all of the signals normally required for prestalk differentiation, but perhaps not for the differentiation of wild-type prespore cells.

Cell type-specific gene expression in developmental chimeras

Chimeric studies using marked cells also permit an analysis of cell autonomous control of cell-specific mRN A expression. Because nearly all car4 ${ }^{-}$cells are diverted to the prespore pathway when devel oped in combination with wild-type cells, and because most wildtype cells become prestalk when developed with car4 mutants, we could only study certain chimeric combinations.

Levels of prestalk expression were examined by devel- opmental Northern blots using chimeras of $2 \%$ ecmA/ lacZ-marked wild-type cells and 98\% unmarked wildtype or car4- cells. The prestalk ecmA and prespore cotB controls show that endogenous prestalk expression is suppressed in the predominant car4 null background, whereas prespore genes are overexpressed (Fig. 5A). Because the ecmA/lacZ fusion is carried on a transformation vector with a neo ${ }^{R}$ marker driven by a Dictyostelium growth-specific promoter, we used levels of neo mRNA to confirm that both chimeric sets contained equal percentages of marked cells (Fig. 5A). N ormally, prestalk cells represent only $\sim 20 \%$ of the developing population. The act15/lacZ studies (see Fig. 4C) indicate that $>80 \%$ of wild-type cells will become prestalk when mixed with the car4 ${ }^{-}$population. Thus, the expression of ecmA/lacZ in JH10 cells is about fourfold greater when codeveloped with car4- ${ }^{-}$cells (Fig. 5A). Although endogenous ecmA expression is low in car4 null cells, this chimera is still able to support normal (cell autonomous) ecmA expression [and prestalk patterning (see Fig. 4A)] of the $2 \%$ population of wild-type $\mathrm{JH} 10$ cells.

Parallel experiments were performed using $2 \%$ cotB/ lacZ-marked car4- cells and 98\% unmarked wild-type or car4 ${ }^{-}$cells. A gain, the endogenous ecmA and cotB genes and the neo transgene yiel ded appropriate and consistent patterns of mRNA expression (Fig. 5B). For either mix, nearly identical $(\geqslant 80 \%)$ percentages of marked cells are predicted to become prespore (see Fig. 4C). Yet, cotB/ lacZ expression in car4 null cells is significantly higher when they are developed in combination with wild-type

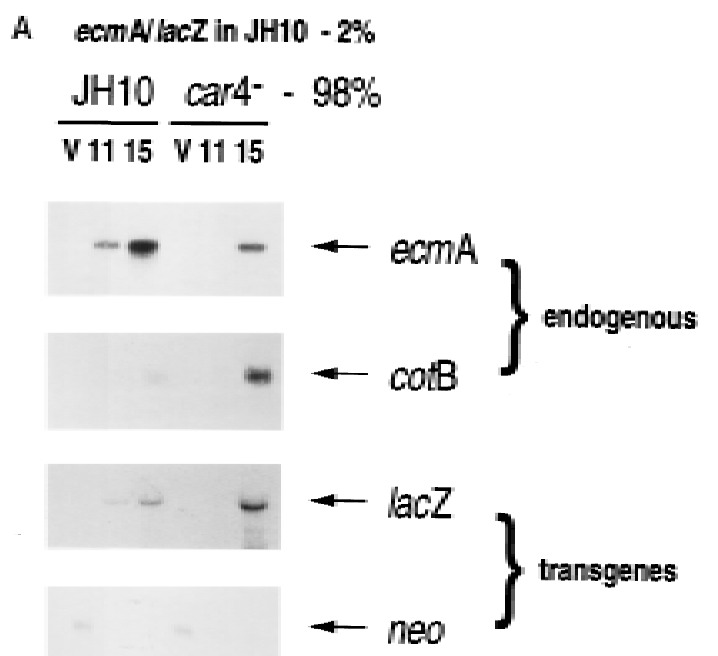
Bi $\cot \mathrm{B}^{\prime} / a c \mathrm{Z}$ in $\operatorname{car} 4^{-}-2 \%$

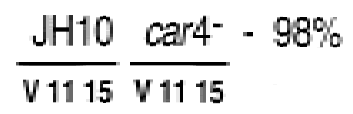

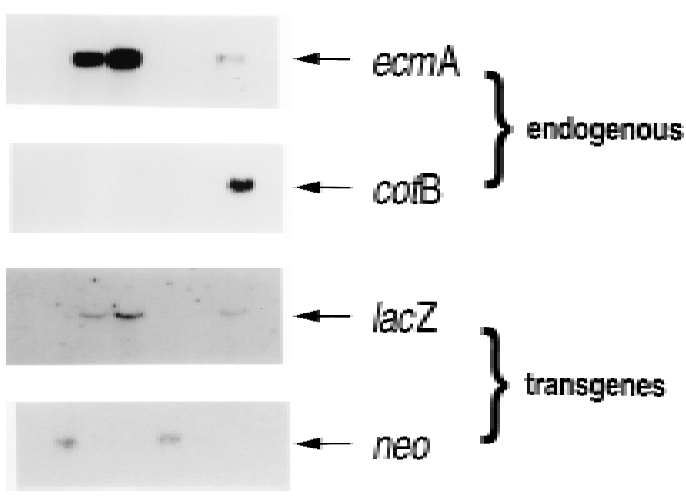

Figure 5. Gene expression in developmental chimeras. (A) ecmA/lacZ expression levels in chimeras. Wild-type JH10 cells marked with the prestalk ecmA/lacZ transgene were mixed with unmarked wild-type JH10 or car4 null cells at 1:49 ratios, respectively, as indicated. Cells were harvested from vegetative growth $(\mathrm{V})$ and plated for synchronous devel opment. At hours indicated, RN As were isolated and hybridized on N orthern blots to ecmA (prestalk), cotB (prespore), neo, and lacZ (prestalk-specific) probes. (B) cotB/lacZ expression levels in chimeras. car4 null cells marked with the prespore cotB/lacZ transgene were mixed with unmarked wild-type $\mathrm{JH} 10$ or car4 null cells at 1:49 ratios, respectively, as indicated. Cells were harvested from vegetative growth (V) and plated for synchronous development. At times indicated, RNAs were isolated and hybridized on Northern blots to ecmA (prestalk), cotB (prespore), neo, and lacZ (prestalk-specific) probes. (B) cotB/lacZ expression levels in chimeras. car4 null cells marked with the prespore cotB/lacZ transgene were mixed with unmarked wild-type JH10 or car4 null cells at 1:49 ratios, respectively, as indicated. Cells were harvested from vegetative growth $(V)$ and plated for synchronous devel opment. At times indicated, RN As were isol ated and hybridized on N orthern blots to ecmA (prestalk), cotB (prespore), neo, and lacZ (prespore-specific) probes. 
cells than in chimeras with unmarked car4 ${ }^{-}$cells (Fig. 5B). These data indi cate that wild-type CAR4 directs two modes of prespore gene regulation. First, as a cell-surface receptor for CAMP in prespore cells, CAR4 can inhibit prespore gene expression in a cell autonomous manner. Second, wild-type CAR4-expressing cells seem to activate prespore expression nonautonomously, presumably through secretion of a stimulatory factor.

Cells that express CAR4 secrete a prespore-differentiation factor

Developing Dictyostelium accumulate sufficient levels of the prestalk morphogen DIF-1 throughout their posterior region to inhibit normal prespore differentiation (Berks and Kay 1990; Schaap 1991; Loomis 1993), yet DIF-1-mediated inhibition of prespore patterns is not observed during the development of wild-type cells. Data from Figures 4C and 5B suggest that wild-type cells produce an extracellular prespore signal; car4- ${ }^{-}$cells respond to this signal but do not produce it. Wereasoned that this secreted prespore factor might serve to decrease the in vivo sensitivity of prespore cells to DIF-1 inhibition and evaluated the ability of differentiating wild-type or car4null cells to accumulate a prespore stimulatory factor in their respective media. Media conditioned by cultured wild-type cells and car4- ${ }^{-}$cells were used for subsequent cAMP-induced differentiations in the presence or absence of a limiting concentration (15 nM) of exogenous DIF-1. The experimental design is outlined in Figure 6A, and the data are presented in Figure 6B.

The data demonstrate (Fig. 6B) that prespore cotB expression in car4 null cells is repressed by car4- medium treated with exogenous DIF-1 but is resistant to DIF-1 inhibition when differentiated with medium conditioned by wild-type JH10 cells. N onetheless, cotB expression in car4 null cells is consistently greater than that observed for $\mathrm{JH} 10$ cells regardless of which medium is used for differentiation (see Fig. 6B). JH10 medium al so promotes somewhat higher levels of cotB expression in JH10 cells than does the car4- medium. These results clearly demonstrate that CAR4-expressing cells are involved in the accumulation of an extracellular factor that augments prespore differentiation. Although it is yet unclear how prestalk differentiation is initiated (Shaulsky et al. 1995), a role for DIF-1 in their ultimate determination is well established (Williams et al. 1989; Berks and Kay 1990; Williams 1995). The various medium preparations have only minimal effect on the relative levels of ecmA prestalk gene expression (Fig. 6B) and lack accumulated DIF-lase (R.R. Kay and A.R. Kimmel, unpubl.). Thus, the secreted factor appears to act specifically on prespore cells, apparently to reduce their sensitivity to inhibition by the prestalk morphogen DIF-1.

\section{Negative regulation of GSK3 by CAR4}

Dictyostelium that lack gskA, the gene for GSK3, have phenotypes that are substantially the opposite of car4 null cells. gskA- cells do not express prespore genes to significant levels and correspondingly have expanded prestalk cell patterns (Harwood et al. 1995). Several data link CAR signaling with GSK3 regulation. Prespore expression in gskA null cells cannot be rescued by extracellular CAMP, and stalk differentiation is not sensitive to inhibition by CAMP as in wild-type cells (Harwood et al. 1995). Other data are consistent with a role for GSK3 in Dictyostelium patterning. LiCl will specifically in-
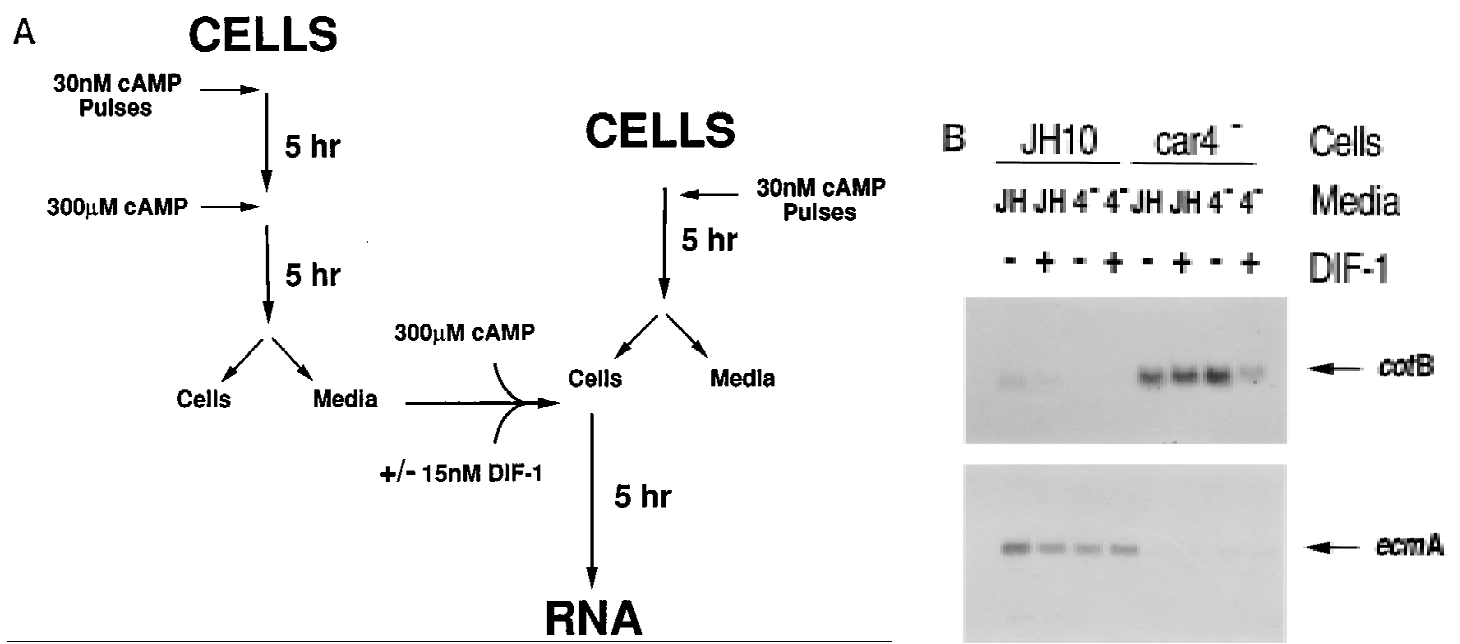

Figure 6. Identification of a prespore regulatory factor in conditioned media. (A) Wild-type JH10 and car4 null cells were harvested from vegetative growth and resuspended for differentiation in suspension cultures. For the first $5 \mathrm{hr}$, cAMP was added at 6-min intervals to a final concentration of $30 \mathrm{~nm}$. Subsequently, cultures were adjusted to $300 \mu \mathrm{M} \mathrm{CAM} \mathrm{P}$, and after $5 \mathrm{hr}$ the conditioned media were collected and adjusted to a further $300 \mu \mathrm{M}$ CAM P and split for treatment with or without 15 nM exogenous DIF-1. Cultures of wild-type $\mathrm{JH} 10$ and car4 null cells that had al ready received CAMP pulses for $5 \mathrm{hr}$ were harvested and resuspended in each of the separate medium preparations, and incubated further. RN As were isolated as indicated. (B) N orthern bl ots of RN As isolated from cells treated with conditioned media and hybridized to the prestalk probe ecmA and the prespore probe cotB. 
hibit GSK3 activity in vitro [Ki $\sim 2 \mathrm{~mm}$ (Klein and M elton 1996; Stambolic et al. 1996; Hedgepeth et al. 1997)], and treatment of Dictyostelium with $\mathrm{LiCl}$ will redirect cell fate, yiel ding a partial phenocopy of gskA null cells (Maeda 1970; Sakai 1973; Van Lookeren Campagne et al. 1988).

To determine whether the phenotypes of the car4 null cells were the result of a loss in GSK3 regulation, we differentiated mutant cells in suspension culture in the presence of varying concentrations of $\mathrm{LiCl}$ and examined patterns of prespore and prestal $k$ gene expression in comparison with wild type (Fig. 7). Typically, untreated car4 null cells (see Fig. 1) expressed prespore cotB to high levels and had reduced levels of prestalk ecmB mRNA. With increasing concentration of $\mathrm{LiCl}$ to $10 \mathrm{~mm}$, we see a near complete rescue of cell-specific gene expression in car4- cells (Fig. 7). These results strongly suggest that GSK3 lies downstream of CAR4 in a pathway that stimulates prestalk patterning. Loss of CAR4 by null mutation would thus yield enhanced prespore gene expression but reduced prestal $k$ differentiation through an increase in GSK3 activity (see Figs. 1, 8, and 9).

\section{Discussion}

The proportioning of prestalk and prespore cells in wildtype Dictyostelium is generally invariant irrespective of the number of cells in the slug (Loomis 1993). Although position within the cell cycle at the time of starvation may contribute to an initial prestalk/prespore choice (Weijer et al. 1984; Gomer and Firtel 1987; Maeda et al. 1989), differentiation is plastic and requires continuous response to activating pathways as well as to lateral inhibition for determining and maintaining constant proportions (Loomis 1993). The differentiation of prestalk and prespore cells is positively regulated by secreted, extracellular CAM P, but we now show that CAM $\mathrm{P}$ receptor responses can be al so varied and antagonistic. The loss of

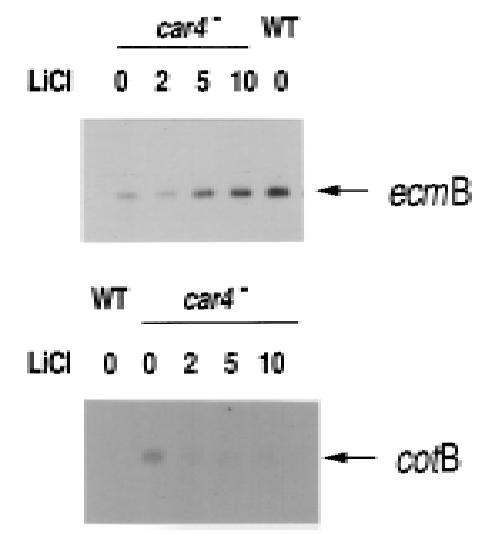

Figure 7. Regulation of cell-specific gene expression in car4 null cells by $\mathrm{LiCl}$. Wild-type $\mathrm{JH} 10$ and car4 null cells were pulsed with cAM P for $4.5 \mathrm{hr}$. The car4 null culture was split and adjusted to $0,2,5$, or $10 \mathrm{~mm} \mathrm{LiCl}$. Pulsing was continued for 30 min, and all cultures were treated with $300 \mu \mathrm{M}$ CAM P. After $5 \mathrm{hr}$ RN As were isolated and hybridized on N orthern blots to the prestalk probe ecmB and the prespore probe cotB.
CAR4 function has contrasting effects on the differentiation, genetic activity, patterning, and fate of prestalk and prespore cells. Abnormalities result from defective intracellular CAMP signal response and failure to produce, but not respond to, a non-cAMP extracellular factor. Some of the regulatory circuits associated with prestalk and prespore differentiation in Dictyostelium and their link with CAR4 signal ing are detailed in Figure 8. They define novel mechanisms for CAMP activation or lateral inhibition of prestalk and prespore differentiation and for determining cell-type proportions and positions during development.

car4- cells exhibit significantly reduced levels of prestalk gene expression and zones of differentiation (Figs. 1 and $4 A$ ). These patterns cannot be rescued in development with wild-type cells, whereas wild-type cells have normal prestalk patterns when developed with car4 mutants. car4 null cells also fail to express wild-type levels of prestalk mRNAs when differentiated in suspension cultures with exogenous CAM P and DIF-1, requisite factors for prestalk differentiation (Fig. 3). car4 null cells produce all the signals necessary for prestalk differentiation and patterning but lack appropriate response. CAR4 plays an essential and autonomous role in intracellular signaling for prestalk differentiation (Fig. 8). CAR4 and CAR2 are the more abundant CAMP receptors on prestalk cells, and elimination of either disturbs prestal $k$ cellular patterns (Saxe et al . 1991a,b, 1993, 1996; Louis et al. 1994; Ginsburg et al. 1995; G.T. Ginsburg and A.R. Kimmel, unpubl.). By analogy with CAR4 we may suggest that CAR2 similarly activates an intracellular signaling pathway for prestalk differentiation and patterning (Fig. 8).

Prespore differentiation is regulated by CAR4 through autonomous and nonautonomous mechanisms (Fig. 8). Increased levels of prespore expression in car4 null cells (Fig. 1) do not result from reduced levels of or response to DIF-1 (Table 1; Figs. 2 and 3C). Enhanced prespore expression is observed during differentiation in the presence of saturating concentrations of CAMP (Fig. 3). It is similarly not caused by limitation of endogenous CAM P through diminished CAMP relay and cannot be rescued by development with wild-type cells. We suggest that CAR4 has a primary and cell autonomous role linked to an intracellular, inhibitory pathway for prespore control. Because extracellular CAMP is nonetheless essential for prespore differentiation (Kimmel and Firtel 1991; Firtel 1995), CAR4 may act antagonstical ly to intracellular circuits activated by CAR1/CAR3 (Fig. 8).

In correspondence with the increase in prespore gene expression, car4 null cells exhibit expanded prespore regions with appearance of prespore cells in prestalk-derived structures (Louis et al. 1994; see al so Fig. 4B). These prespore patterning defects are rescued in chimeric slugs with wild-type cells (Fig. 4B). Conversely, most wildtype cells will not differentiate into prespore/spore cells in chimeric development with car4 null cells (Fig. 4C), and the few wild-type prespore cells that do appear exhibit abnormal patterns (Fig. 4B). Prespore positioning and determination appears to be nonautonomously regu- 


\section{Prestalk Cell}

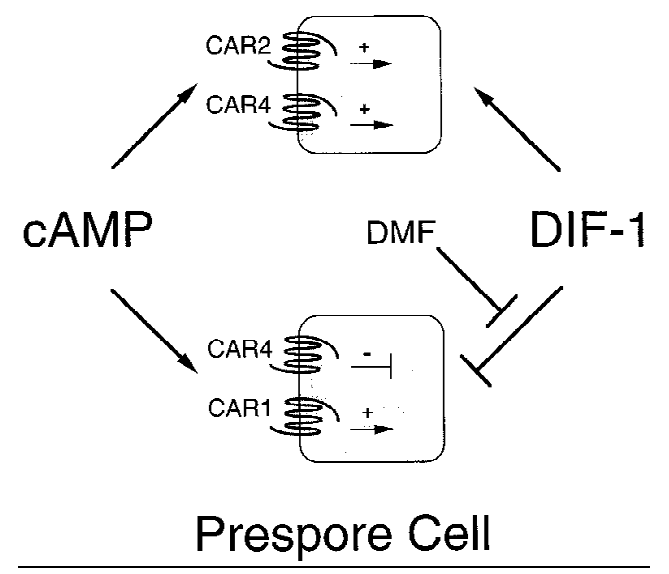

Figure 8. Autonomous and nonautonomous roles for CAR4 regulation of prestalk and prespore differentiation. Prestalk differentiation requires the extracellular signals CAMP and DIF-1. Elimination of CAR4 greatly reduces expression of prestalk genes and disturbs prestalk cellular patterns. However, because car4- cells accumulate sufficient levels of CAM P and DIF-1 for prestalk differentiation, CAR4 must act autonomously to activate prestalk pathways. Based on other data (Saxe et al. 1993) and by analogy with CAR4 function, we suggest further that CAR2 also activates an intracellular signaling pathway for prestalk differentiation. Extracellular CAMP both activates and inhibits prespore differentiation through separate surface receptors. We suggest antagonistic mechanisms for CAM P regulation of prespore differentiation through CAR 1 and/or CAR3 and CAR4, both acting cell autonomously. The prestalk morphogen DIF-1 is an inhibitor of prespore differentiation. DMF is an extracellular factor that modulates the sensitivity of prespore cells to DIF-1 inhibition but does not alter the response of prestalk cells. Active CAR4 is required by cells for DMF accumulation, thus defining a nonautonomous role for CAR4 in prespore differentiation. Currently we do not know if a specific population of cells is involved in DMF production. Epistatic interactions: The model positions DMF to antagonize DIF-1 inhibition of prespore differentiation, but the data cannot exclude a mechanism for the direct activation of prespore differentiation. (Pointed arrow) Activating pathways; (T-shaped arrow) inhibiting pathways.

lated by CAR4. Although positioning of prespore cells may be affected by defects in CAMP signaling, a distinct extracellular mechanism must account for the inability of wild-type cells to sporulate at normal frequencies in chimeras with $90 \%$ car4 null cells (Fig. 4C). More specifically, CAR4-expressing cells produce a critical factor that modulates the sensitivity of prespore cells to inhibition by DIF-1 (Fig. 6B). This DIF-1 modulation factor (DMF) is both limiting in car4 null cells and not essential for their prespore differentiation.

Although prespore differentiation is sensitive to inhibition by DIF-1 in suspension culture, it may not be adequate to effect complete inhi bition of prespore differentiation during normal devel opment (Berks and Kay 1990; Schaap 1991; Loomis 1993). The action of DM F may resolve this apparent paradox. DM F decreases, but does not eliminate, the sensitivity of prespore cells to inhibition by DIF-1. DMF does not affect prestalk expression. Its action appears to be cell type specific and unlikely merely to sequester or degrade DIF-1. Furthermore, during CAMP-induced differentiation, when DMF production is maximized, accumulation of DIF-1 dechlorinase, an obligatory enzyme in the first step of DIF-1 degradation, is suppressed. Preliminary fractionation studies indicate that it is distinct from other potential prespore activators (see Loomis 1996; A.R. Kimmel, unpubl.). Although our epistatic model (see Fig. 8) positions DMF to antagonize di rectly the inhibitory function of DIF-1, our data cannot exclude an indi rect effect through activation of a separate pathway. Neither is it clear which CAR4expressing cells contribute to DMF production.

Prespore differentiation is inhibited by CAM $P$ through CAR4 (cell autonomously) and by DIF- 1 but is activated by CAMP through CAR1 and/ or CAR3 and by DM F (Fig. 8). In the absence of DM F, negative pathways controlled by CAR4 and DIF-1 are sufficient to restrict prespore differentiation of wild-type cells. car4 null cells, however, lack the inhibitory CAR4 circuit and are less dependent on derepression of the DIF-1 inhibitory pathway for prespore differentiation. Prespore expression in car4 null cel Is is still sensitive to repression by DIF-1 (Fig. 3C) and derepression by DMF (Figs. 5B and 6B). Thus, car4 ${ }^{-}$ cells differentiated in combination with DMF-producing, wild-type cells express prespore genes beyond their al ready el evated level (Fig. 5B). M edium conditioned by differentiating wild-type cells, but not by the car4 ${ }^{-}$cells, partially overcomes the inhibition by DIF-1 on prespore gene expression (Fig. 6B).

The predominant class of CAMP receptors on prestal $\mathrm{K}$ cells [CAR4/CAR2 Johnson et al. 1992; Louis et al. 1994; Saxe et al. 1996; J.M. Louis and A.R. Kimmel, unpubl.)] have significantly lower affinities than do those on prespore cells [CAR1/CAR3 Johnson et al. 1992, 1993; Ginsburg et al. 1995; Yu and Saxe 1996; Gollop and Kimmel 1997; J.M. Louis and A.R. Kimmel, unpubl.)]. It is suggested that CARs exhibit differential responses to subsaturating or adapting concentrations of CAM P (Chen et al. 1996). Thus, it is difficult to predict definitively which specific intracellular responses are affected by the loss of CAR4, a low-affinity receptor. However, there are two autonomous, intracellular pathways, critical for prestalk and prespore differentiation, that may lie downstream of the CARs. Prestalk and prespore cells require active CAMP-dependent protein kinase A (PKA) for differentiation (Harwood et al. 1992; M ann and Firtel 1993). PKA activity can be regulated by the intracellular pool of CAMP that results from CAR-coupled stimulation of adenylyl cyclase (Kimmel and Firtel 1991; Chen et al. 1996). Although their dose-dependent responses to CAMP may differ, all of the CARs may be capable of adenylyl cyclase activation (Pupillo et al. 1992; A.R. Kimmel, unpubl.) and, hence, PKA activation. Reduced cyclase activation in car4- prestalk cells potentially could inhibit the PKA-dependent regulation of prestalk differentiation.

Another serine/threonine kinase, GSK3, appears to be 
CAR regulated. gskA ${ }^{-}$cells (GSK3 null cells) have a cell autonomous phenotype that is substantially opposite that of the car4 null cells (Harwood et al. 1995). In the absence of GSK3, prestalk ecmB gene expression is enhanced while prespore expression is barely detectable. Furthermore, gskA ${ }^{-}$cells are insensitive to CAM P stimulation of prespore gene expression and CAMP inhibition of stalk differentiation. It has been argued that certain CARs (potentially CAR1/CAR3) may be positive effectors for GSK activity (Harwood et al. 1995). Our data indicate that CAR4 promotes prestalk, and inhibits prespore, differentiation by decreasing GSK3 activity. In context with the model for CAR control of prestalk and prespore differentiation, CAR4 and CAR1/CAR3 may be antagonostic and epistatic to GSK3 (Fig. 9). An additional component in this sequence may now be invoked. We have shown that slugs that lack the gene for the RIN G/ zipper protein rZIP are phenotypically similar to the car4 null cells (Balint-Kurti et al. 1997). Defining epistatic relationships among CAR4, CAR1, CAR3, rZIP, GSK3, and PKA will be of critical significance in understanding CAR regulatory pathways.

Regulation of Dictyostelium cell fate by CAMP may be anal ogous to signal ing via Wnt/Wg morphogens in Xenopus and Drosophila (see Fig. 9). Like cAM P receptors, the Wnt/Wg receptors (Fz) are serpentine, seven-transmembrane members (Bhanot et al. 1996) that may be linked to cell autonomous and nonautonomous regulatory pathways (Krasnow and Adler 1994). Fz2 (and CAR4)-mediated inhibition of GSK3 appears to regulate pattern formation by a cell autonomous mechanism. Down-regulation of GSK3 activity in the ventral equatorial region of Xenopus blastomeres establ ishes secondary dorsal axes, whereas ectopic expression of activated GSK3 in dorsal structures leads to their ventralization ( $\mathrm{He}$ et al. 1995; Pierce and Kimel man 1995). In Drosophila, wg mutants exhibit diminished expression of the segment polarity gene engrailed (en), whereas generalized expression of wg or mutants of shaggy (GSK3) expand the boundary of en expression (see Perimmon 1994). Both the CAMP and
Wnt/Wg systems utilize additional secreted factors to regulate effective morphogen concentrations (Fig. 9). In Dictyostelium, phophodiesterase (PDE) enzymatically degrades CAM P to 5'-AM P; in turn, PDE activity is regulated by another specific inhibitor, PDE-I (Franke et al. 1991). For Wnt/Wg, the secreted fz-related protein family, including Frzb and FRP, has very high and specific affinity for these morphogens that antagonizes their activity (Leyns et al. 1997; Wang et al. 1997; J. Rubin, X. $\mathrm{He}$, and $\mathrm{H}$. Varmus, pers. comm.). These data support an ancient appearance for body plan control via receptormediated regulation of GSK3 activity.

In addition, the Wnt and CAM $P$ receptors are linked to pathways that activate and inhibit fate patterns. The Wnt-5A class will antagonize the dorsalizing effects of Wnt-1 members on early Xenopus embryogenesis but induce dorsal axis duplication in conjunction with human Fz5 (He et al. 1997). Also, whereas Wnt-8 has dorsalizing activity in early embryos, it is a presumptive ventralizing factor during gastrulation. In Dictyostelium, di stinct CAR subtypes are proposed to differentially regulate a common intracellular circuit for prespore differentiation (Fig. 9). We would suggest that analogous mechanisms for Wnt signaling in Xenopus could potentially activate or inhibit GSK pathways. However, indirect effects, perhaps on cell adhesion, cannot be excluded (Torres et al. 1996). Finally, it may be speculated that the Fz (Wnt/Wg) and CAR pathways converge at GSK3 through a common target, and because GSK 3 activity can be modulated by phosphorylation at multiple sites (C ook et al. 1996), this may also involve a shared kinase/ phosphatase cascade and additional downstream components.

\section{Materials and methods}

Dictyostelium: DNA-mediated transformation, growth, development, and differentiation in suspension cultures

Wild-type JH10 and car4 null lines were transformed by electroporation, selected for G418 resistance, and grown in HL5 medium in the presence of $20 \mu \mathrm{g} / \mathrm{ml}$ of $\mathrm{G} 418$ as required (Louis

Secreted
Regulator Ligand $\begin{gathered}\text { 7-Span } \\ \text { Receptor }\end{gathered} \begin{gathered}\text { Intracellular } \\ \text { Effector }\end{gathered}$ Cell Fates
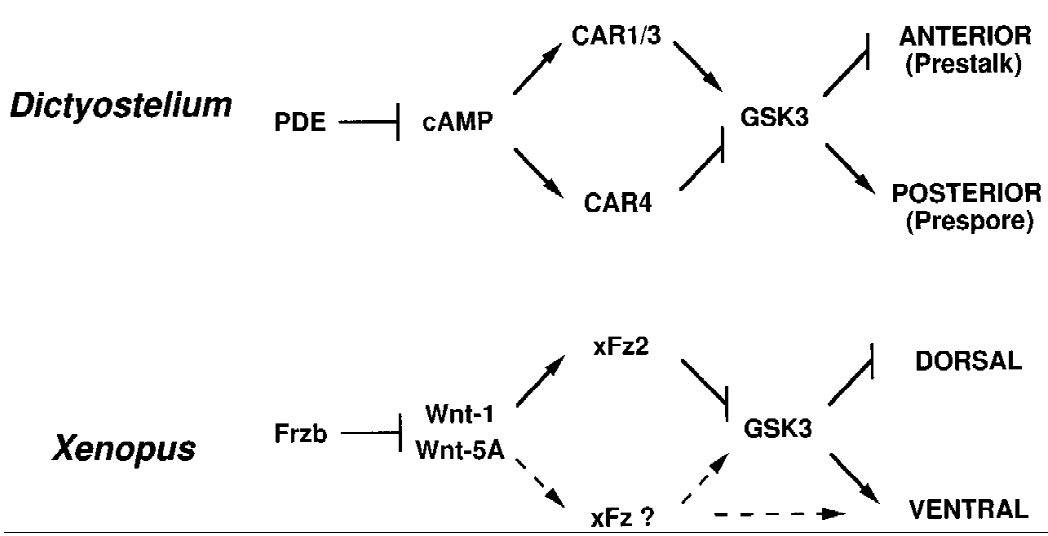

Figure 9. Parallel pathways for axes formation in Dictyostelium and Xenopus. In Dictyostelium, PDE will degrade the secreted morphogen CAMP, which will activate the CAR family. CAR4 and CAR $1 / 3$ act antagonistically and converge at GSK3. High GSK3 levels promote prespore differentiation and inhibit prestalk patterns. LiCl will stimulate prestalk differentiation through inhibition of GSK3. In Xenopus, the Frzb family of secreted proteins can bind Wnt morphogens with high affinity. Activation of Xenopus Fz2-type receptors during early embryogenesis by the Wnt-1 class down-regulates GSK3 activity and stimulates dorsal structures. The Wnt-5A class will antagonize the dorsalizing action of Wnt-1. Broken lines indi cate potential pathways for ventral activation via another Fz receptor. Direct activation of GSK3 is suggested by comparison with CAR signaling in Dictyostelium (see above). 
et al. 1993). Cells were grown to at $2 \times 10^{6}$ cells $/ \mathrm{ml}$, washed, counted, mixed at appropriate ratios, and developed on nitrocellul ose filters $\left(0.5 \times 10^{7}\right.$ to $1 \times 10^{7}$ cells $\left./ \mathrm{cm}^{2}\right)$ in $10 \mathrm{~mm}$ sodium phosphate (pH 6.4), $2 \mathrm{mM} \mathrm{M} \mathrm{gCl}_{2}$, and $0.2 \mathrm{mM} \mathrm{CaCl}_{2}$. Cells were differentiated in suspension culture under conditions that do not permit endogenous CAMP signaling (Louis et al. 1993), adjusted to $\sim 30 \mathrm{nM}$ CAMP at 6-min intervals for $5 \mathrm{hr}$, and then maintained continuously at $\geqslant 300 \mu \mathrm{M} C A M P, 10 \mathrm{mM}$ adenosine, $2 \mathrm{U} / \mathrm{ml}$ of ADA; and/or $300 \mathrm{nM}$ DIF-1. LiCl was added to CAM Ppulsed cultures 30 min prior to treatment with $300 \mu \mathrm{M} \mathrm{CAMP.}$

Developmental RNA and $\beta$-galactosidase expression patterns

Total RNA was prepared from cells, electrophoretically separated, and blotted for hybridization (Kimmel 1987). Probes were radiolabeled by the random primer method and hybridized to RN A blots at $37^{\circ} \mathrm{C}$ in $0.8 \mathrm{M} \mathrm{Na}^{+}$and $50 \%$ (vol/vol) formamide. Chimeric organisms were developed on nitrocellulose filters and stained for $\beta$-gal actosi dase activity (Richardson et al. 1994).

\section{CAMP and DIF-1 assays}

Wild-type JH10 and car4 null cells were developed on filters, and the total accumulated CAMP was assayed (Kimmel 1987). These same cells were differentiated in suspension cultures with and without $300 \mu \mathrm{M}$ CAMP, and DIF-1 was extracted and bioassayed (Kay 1987). For radiolabeling of DIF-1, cells were differentiated in $25 \mathrm{ml}$ in $10 \mathrm{~mm}$ sodium phosphate (pH 6.4), 1 $\mathrm{\mu Ci} / \mathrm{mi}$ of ${ }^{36} \mathrm{Cl}(\sim 2 \mathrm{mM} \mathrm{NaCl})$ with CAMP, extracted, separated by thin layer chromatography (Kay et al . 1992), and imaged (M olecular Dynamics).

\section{Acknowledgments}

We are grateful to P. Balint-Kurti, R.R. Kay, L. Kim, W.F. Loomis, X. Mu, B. Oliver, K. Rogers, P. Schwartzberg, and especially A. Harwood for critical discussions and to the Firtel and Williams laboratories for invaluable reagents. We al so thank J. Rubin, $X$. $\mathrm{He}$, and $\mathrm{H}$. Varmus for communicating unpublished data.

The publication costs of this article were defrayed in part by payment of page charges. This article must therefore be hereby marked "advertisement" in accordance with 18 USC section 1734 solely to indicate this fact.

\section{References}

A be, K. and K. Yanagisawa. 1983. A new class of rapid developing mutants in Dictyostelium discoideum: Implications for cyclic AMP metabolism and cell differentiation. Dev. Biol. 95: 200-210.

Alcedo, J., M. Ayzenzon, T. Von Ohlen, M. Noll, and J.E. Hooper. 1996. The Drosophila smoothened gene encodes a seven-pass membrane protein, a putative receptor for the hedgehog signal. Cell 86: 221-232.

Bal int-Kurti, P., G. Ginsburg, O. Rivero-Lezcano, and A.R. Kimmel. 1997. rZIP, a RIN G-leucine zipper protein that regulates cell fate determination during Dictyostelium development. Development 124: 1203-1213.

Berks, M. and R.R. Kay. 1990. Combinatorial control of cell differentiation by CAMP and DIF-1 during development of Dictyostelium discoideum. Development 110: 977-984.

Bhanot, P., M. Brink, C.H. Samos, J.-C. Hsieh, Y. Wang, J.P. Macke, D. Andrew, J. N athans, and R. N usse. 1996. A new member of the frizzled family from Drosophila functions as a Wingless receptor. Nature 382: 225-230.

Chen, M.-Y., R.H Insall, and P.N. Devreotes. 1996. Signaling through chemoattractant receptors in Dictyostelium.
Trends Genet. 12: 52-57.

Cook, D., M.J. Fry, K. Hughes, R. Sumathipala, J.R. Woodgett, and T.C. Dale. 1996. Wingless inactivates glycogen sythase kinase-3 via an intracellular signaling pathway which involves a protein kinase C. EMBO J. 15: 4526-4536.

Firtel, R.A. 1995. Integration of signaling information in controlling cell-fate decisions in Dictyostelium. Genes \& Dev. 9: 1427-1444.

Franke, J., M. Faure, L. Wu, A.L. Hall, G.J. Podgorski, and R.H Kessin. 1991. Cyclic nucleotide phosphodiesterase of Dictyostelium discoideum and its glycoprotein inhibitor: Structure and expression of their genes. Dev. Genet. 12: 98-112.

Ginsburg, G. and A.R. Kimmel. 1989. Inositol trisphosphate and diacylglycerol can differentially modulate gene expression during Dictyostelium development. Proc. Natl. Acad. Sci. 86: 9332-9336.

Ginsburg, G.T., R. Gollop, Y. Yu, J.M. Louis, C.L. Saxe, and A.R. Kimmel. 1995. The regulation of Dictyostelium development by transmembrane signaling. J. Euk. Microbiol. 42: 200-205.

Gollop, R. and A.R. Kimmel. 1997. Control of cell-type specific gene expression in Dictyostelium by the general transcription factor GBF. Development (in press).

Gomer, R.H. and R.A. Firtel. 1987. Cell-autonomous determination of cell-type choice in Dictyostelium development by cell-cycle phase. Science 237: 758-762.

Harwood, A.J., N .A. Hopper, M.N Simon, D.M. Driscoll, and J.G Williams. 1992. Culmination in Dictyostelium is regulated by the CAMP dependent protein kinase. Cell 69: 615-624.

Harwood, A.J., S.E Plyte, J. Woodgett, H. Strutt, and R.R. Kay. 1995. Glycogen synthase kinase 3 regulates cell fate in Dictyostelium. Cell 80: 139-148.

He, X., J.P. Saint-Jeannet, J.R. Woodget, H.E. Varmus, and I.B. Dawid. 1995. Glycogen synthase kinase-3 and dorsalventral patterning in Xenopus embryos. Nature 374: 617-622.

$\mathrm{He}, \mathrm{X}$., J.P. Saint-Jeannet, Y. Wang, J. N athans, I. Dawid, and H. Varmus. 1997. A member of the frizzled protein family mediating axis induction by Wnt-5A. Science 275: 1652-1654.

Hedgepeth, C.M., L.J. Conrad, J. Zhang, H.-C. Huang, V.M.Y. Lee, and P.S. Klein. 1997. Activation of the Wnt signaling pathway: A molecular mechanism for lithium action. Dev. Biol. 185: 82-91.

Insall, R., O. N ayler, and R.R. Kay. 1992. DIF-1 induces its own breakdown in Dictyostelium. EMBO J. 11: 2849-2854.

Insall, R.H., R.D.M. Soede, P. Schaap, and P.N . Devreotes. 1994. Two CAM $P$ receptors activate common signaling pathways in Dictyostelium. Mol. Biol. Cell 5: 703-711.

Johnson, R.L., P.M.J. van Haastert, A.R. Kimmel, C.L. Saxe, B. Jastorff, and P.N. Devreotes. 1992. The cyclic nucleotide specificity of three cAM P receptors in Dictyostelium. J. Biol. Chem. 267: 4600-4607.

Johnson, R.L., C.L. Saxe, R. Gollop, A.R. Kimmel, and P.N. Devreotes. 1993. Identification and targeted gene disruption of CAR3, a CAM P receptor subtype expressed during multicellular stages of Dictyostel ium devel opment. Genes \& Dev. 7: 273-282.

Kay, R.R. 1987. Cell differentiation in monolayers and the investigation of slime mold morphogens. Methods Cell Biol. 28: 433-448.

Kay, R.R., G.W. Taylor, K.A. Jermyn, and D. Traynor. 1992. Chlorine-containing compounds produced during Dictyostelium development-Detection by labeling with $\mathrm{Cl}-36$. Biochem. J. 28: 155-161.

Kimmel, A.R. 1987. Different molecular mechanisms for CAM P regulation of gene expression during Dictyostelium devel opment. Dev. Biol. 122: 163-171. 
Kimmel, A.R. and R.A. Firtel. 1991. CAMP signal transduction pathways regulating development of Dictyostelium discoideum. Curr. Opin. Genet. Devel. 1: 383-390.

Klein, P.S. and D.A. M elton. 1996. A molecular mechanism for the effect of lithium on development. Proc. Natl. Acad. Sci. 93: 8455-8459.

Klein, P.S., T.J. Sun, C.L. Saxe, A.R. Kimmel, R.L. Johnson, and P.N. Devreotes. 1988. A chemoattractant receptor controls development in Dictyostelium discoideum. Science 241: 1467-1472.

Krasnow, R.E. and P.N. Adler. 1994. A single frizzled protein has a dual function in tissue polarity. Development 120: 1883-1893.

Leyns, L., T. Bouwmeester, S.-H. Kim, S. Piccolo, and E.M. De Robertis. 1997. Frzb-1 is a secreted antagonist of Wnt signaling expressed in the Spemann organizer. Cell 88: 747-756.

Loomis, W.F. 1993. Lateral inhibition and pattern formation in Dictyostelium. Curr. Top. Dev. Biol. 28: 1-46.

- - 1996. Genetic networks that regulate development in Dictyostelium cells. Microbiol. Rev. 60: 135-150.

Louis, J.M., C.L Saxe, and A.R. Kimmel. 1993. Two transmembrane signal ing mechanisms control expression of the CAMP receptor gene CAR1 during Dictyostelium development. Proc. Natl. Acad. Sci. 90: 5969-5973.

Louis, J.M., G.T Ginsburg, and A.R. Kimmel. 1994. The CAMP receptor CAR4 regulates axial patterning and cellular differentiation during late development in Dictyostelium discoideum. Genes \& Dev. 8: 2086-2096.

Maeda, Y. 1970. Influence of ionic conditions on cell differentiation and morphogenesis of the cellular slime molds. Dev. Growth Differ. 12: 217-227.

Maeda, Y., T. Ohmori, T. A be, F. A be, and A. Amagai. 1989. Transition of starving Dictyostelium cells to differentiation phase at a particular position of the cell cycle. Differentiation 41: 169-175.

Mann, S.K.O. and R.A. Firtel. 1993. cAMP-dependent protein kinase differentially regulates prestalk and prespore differentiation during Dictyostelium development. Development 119: 135-146.

Miller, J.R. and R.T Moon. 1996. Signal transduction through $\beta$-catenin and specification of cell fate during embryogenesis. Genes \& Dev. 10: 2527-2539.

Perrimon, N. 1994. The genetic basis of patterned baldness in Drosophila. Cell 76: 781-784.

- - - 1996. Serpentine proteins slither into the wingless and hedgehog fields. Cell 86: 513-516.

Pierce, S.B. and D. Kimelman. 1995. Regulation of Spemann organizer formation by the intracellular kinase Xgsk-3. De velopment 121: 755-765.

Pupillo, M., R. Insall, G.S. Pitt, and P.N. Devreotes. 1992. Multiple cyclic AMP receptors are linked to adenylyl cyclase in Dictyostelium. Mol. Biol. Cell 3: 1229-1234.

Richardson, D.L., W.L. Loomis, and A.R Kimmel. 1994. Progression of an inductive signal activates sporulation in Dictyostelium discoideum. Development 120: 2891-2900.

Sakai, Y. 1973. Cell type conversion in isolated prestalk and prespore fragments of the cellular slime mold Dictyostelium discoideum. Dev. Growth Differ. 15: 11-19.

Saxe, C.L., R.L. Johnson, P.N. Devreotes, and A.R. Kimmel. 1991a. Expression of a cAM P receptor gene of Dictyostelium and evidence for a multigene family. Genes \& Dev. 5: 1-8.

- - . 1991b. M ulti ple genes for cell surface CAM $P$ receptors in Dictyostelium discoideum. Dev. Genet. 12: 6-13.

Saxe, C.L., G.T. Ginsburg, J.M. Louis, R. Johnson, P.N. Devreotes, and A.R. Kimmel. 1993. CAR2, a prestalk CAMP receptor required for normal tip formation and late develop- ment of Dictyostelium discoideum. Genes \& Dev. 7: 262272.

Saxe, C.L., Y. Yu, C. Jones, A. Bauman, and C. Haynes. 1996. The CAM P receptor subtype CAR2 is restricted to a subset of prestalk cells during Dictyostelium development and displays unexpected DIF-1 responsiveness. Dev. Biol. 174: 202213.

Schaap, P. 1991. Intercellular interactions during Dictyostelium development. In Microbial cell-cell interactions (ed. M. Dworkin), pp. 147-178. American Society for M icrobiology, Washington, D.C.

Shaulsky, G., A. Kuspa, and W.F. Loomis. 1995. A multidrug resistance transporter/serine protease gene is required for prestalk specialization in Dictyostelium. Genes \& Dev. 9: $1111-1122$.

Soede, R.D.M., R.H. Insall, P.N . Devreotes, and P. Schaap. 1994. Extracellular CAMP can restore development in Dictyostelium cells lacking one, but not two subtypes of early CAM P receptors CARs. Devel opment 120: 1997-2002.

Soede, R., N.A. Hopper, J.G. Williams, and P. Schaap. 1996. Extracellular CAMP depletion triggers stalk gene expression in Dictyostelium: Disparities in developmental timing and dose dependency indicate that prespore induction and prestalk repression by CAM P are mediated by separate signaling pathways. Dev. Biol. 177: 152-159.

Spek, W., K. Van Drunen, R. Van Eijk, and P. Schaap. 1988. Opposite effects of adenosine on two types of CAM P-induced gene expression in Dictyostelium indicate the involvement of at least two different intracellular pathways for the transduction of CAMP signals. FEBS Lett. 228: 231-234.

Stambolic, V., L. Ruel, and J.R. Woodgett. 1996. Lithium inhibits glycogen synthase kinase- 3 activity and mimics Wingless signaling in intact cells. Curr. Biol. 6: 1664-1668.

Sun, T.J. and P.N. Devreotes. 1991. Gene targeting of the aggregation stage CAM P receptor CAR1 in Dictyostelium. Genes $\&$ Dev. 5: 572-582.

Theibert, A. and P.N. Devreotes. 1984. Adenosine and its derivatives inhibit the CAMP signaling response in Dictyostelium discoideum. Dev. Biol. 106: 166-173.

Torres, M.A., J.A. Yang-Snyder, S.M. Purcell, A.A. DeM arais, L.L. M cGrew, and R.T. Moon. 1996. Activities of the Wnt-1 class of secreted signaling factors are antagonized by the Wnt-5A class and by a dominant negative cadherin in early Xenopus development. J. Cell Biol. 133: 1123-1137.

van den Heuvel, M. and P.W. Ingham. 1996. smoothened encodes a receptor-like serpentine protein required for hedgehog signalling. Nature 382: 547-551.

Van Lookeren Campagne, M.M., M. Wang, W. Spek, D. Peters, and P. Schaap. 1988. Lithium respecifies cyclic AMP-induced cell-type specific gene expression in Dictyostelium. Dev. Genet. 9: 589-596.

Wang, S., M. Krinks, K. Lin, F. Luyten, and M.M. Moos. 1997. Frzb, a secreted protein expressed in the Spemann organizer, binds and inhibits Wnt-8. Cell 88: 757-766.

Weijer, C.J., G. Duschl, and C.N. David. 1984. Dependence of cell-type proportioning and sorting on cell cycle phase in Dictyostelium discoideum. J. Cell Sci. 70: 133-145.

Williams, J. 1995. M orphogenesis in Dictyostelium: N ew twists to a not-so-old tale. Curr. O pin. Genet. Dev. 5: 426-431.

Williams, J.G., K.T. Duffy, D.P. Lane, S.J. McRobbie, A.J., Harwood, D. Traynor, R.R. Kay, and K.A. Jermyn. 1989. Origins of the prestalk-prespore pattern in Dictyostelium development. Cell 59: 1157-1163.

Yu, Y. and C.L. Saxe. 1996. Differential distribution of the CAM P receptors CAR2 and CAR3 during Dictyostelium development. Dev. Biol. 173: 353-356. 


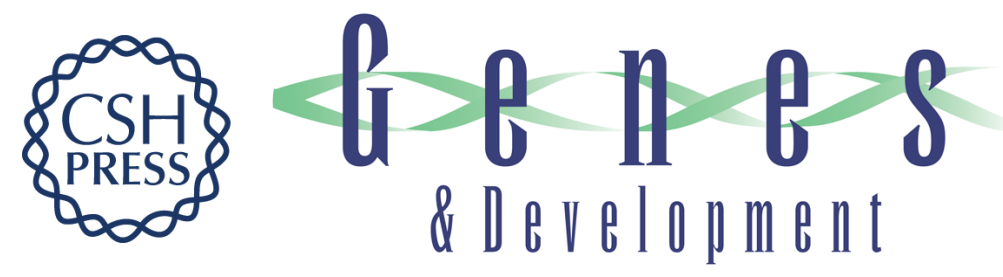

\section{Autonomous and nonautonomous regulation of axis formation by antagonistic signaling via 7-span cAMP receptors and GSK3 in Dictyostelium}

Gail T. Ginsburg and Alan R. Kimmel

Genes Dev. 1997, 11:

Access the most recent version at doi:10.1101/gad.11.16.2112

\section{References This article cites 62 articles, 27 of which can be accessed free at: http://genesdev.cshlp.org/content/11/16/2112.full.html\#ref-list-1}

\section{License}

Email Alerting

Service

Receive free email alerts when new articles cite this article - sign up in the box at the top right corner of the article or click here.

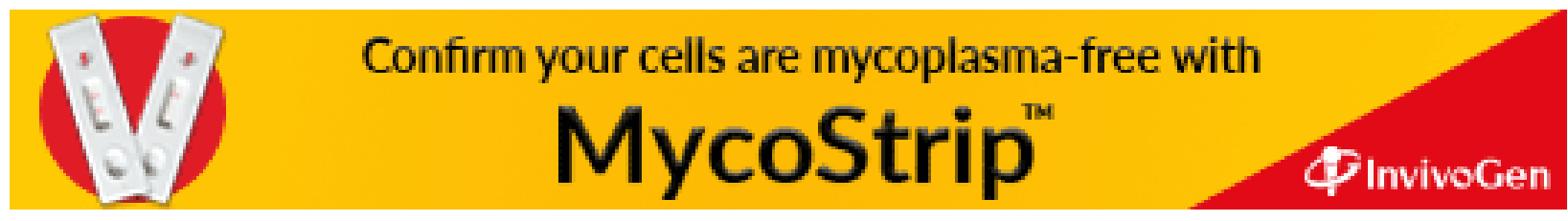

